\title{
Drug Regimen for Patients after a Pneumonectomy
}

\author{
Noheul Kim and Ronny Priefer*(D) \\ Massachusetts College of Pharmacy and Health Sciences, MCPHS University, Boston, MA 02115, USA; \\ nkim5@stu.mcphs.edu \\ * Correspondence: ronny.priefer@mcphs.edu
}

check for

updates

Citation: Kim, N.; Priefer, R. Drug Regimen for Patients after a Pneumonectomy. J. Respir. 2021, 1, 114-134. https://doi.org/10.3390/ jor1020013

Academic Editor: Cesar A. Moran

Received: 23 February 2021

Accepted: 9 April 2021

Published: 13 April 2021

Publisher's Note: MDPI stays neutral with regard to jurisdictional claims in published maps and institutional affiliations.

Copyright: (c) 2021 by the authors. Licensee MDPI, Basel, Switzerland. This article is an open access article distributed under the terms and conditions of the Creative Commons Attribution (CC BY) license (https:/ / creativecommons.org/licenses/by/ $4.0 /)$.

\begin{abstract}
Pneumonectomy is an entire lung removal and is indicated for both malignant and benign diseases. Due to its invasiveness and postoperative complications, pneumonectomy is still associated with high mortality and morbidity. Appropriate postoperative management is crucial in pneumonectomy patients to improve quality of life and overall survival rates. Diverse drug regimens are under development to be used in adjuvant chemotherapy or to improve respiratory health after a pneumonectomy. The most common causes for a pneumonectomy are non-small cell lung cancer, malignant pleural mesothelioma, and tuberculosis; thus, an appropriate drug regimen is necessary. The uncommon incidence of pneumonectomy cases remains the major obstacle in studies of postoperative drug regimens. As the majority of current studies include post-lobectomy and post-segmentectomy patients, it is highly recommended that further research of postoperative drug regimens be focused on post-pneumonectomy patients.
\end{abstract}

Keywords: pneumonectomy; non-small cell lung cancer; malignant pleural mesothelioma; tuberculosis; respiratory health; drug regimen

\section{Introduction}

Pneumonectomy is a surgical treatment wherein the entire lung of a patient is removed. Although an uncommon procedure, in advanced cases of cancer as well as in chronic lung infection, it may become necessary. More preferable to pneumonectomies are lobectomies and segmentectomies due to lower peri- and postoperative risks. For pneumonectomy patients, the rate of postoperative complications is approximately $30-40 \%$ [1-3]. The 30-day postoperative mortality rate is $\approx 5 \%$ for non-small cell lung cancer (NSCLC) patients, with a 5 -year survival rate of only $38 \%$ [4]. It has been reported that the mortality rate increases for patients who undergo a right- vs. left-sided pneumonectomy. Although the difference in overall 5-year survival between the two is not statistically significant [5], right-sided pneumonectomies are well known as a predictor of higher 30- and 90-day mortality [1,5]. The major cause of increased mortality after right-sided pneumonectomy has not been fully determined; however, several studies have implied that the development of bronchopleural fistula could be a significant factor for the high mortality rate. Due to anatomical differences, right-sided pneumonectomy is more likely to require extensive resections [6]. A retrospective study illustrates that this possibly increases the risk of bronchopleural fistulas [6]. Right-sided pneumonectomy is also related to the increased risk of postpneumonectomy syndrome $[7,8]$. Although postpneumonectomy syndrome is rare, it can be fatal, and it is associated with other complications and severely diminished pulmonary functions [8,9].

While the majority of pneumonectomies are indicated for malignant diseases, benign indications still account for $\approx 6 \%$ of pneumonectomy cases [3]. Pneumonectomy for benign diseases is well known as a risk factor for increasing morbidity and mortality. According to a nationwide study, the rate of postoperative complications is higher in benign vs. malignant patients (53\% vs. 39\%) [3]. In addition, the postoperative in-hospital mortality rate for benign diseases is approximately four times higher than that of malignant diseases [3]. With regard to specific indications, infection is the most frequent cause of pneumonectomy 
for benign diseases, with tuberculosis patients accounting for more than $15 \%$ of them [3]. Patients with tuberculosis may undergo a pneumonectomy for either drug-resistant tuberculosis or a tuberculosis-destroyed lung. It has been reported that after pulmonary resection, patients infected with drug-resistant tuberculosis can achieve higher than $90 \%$ of cure rate in combination therapy $[10,11]$. For patients with a tuberculosis-destroyed lung, pneumonectomy is a very effective treatment for the sequelae of pulmonary tuberculosis, resulting in a 5-year survival rate of $89-97 \%[12,13]$. Unlike infectious diseases, pneumonectomy for trauma is extremely rare and generally not recommended [14,15]. As a result of its very high postoperative mortality, trauma pneumonectomy is avoided unless pulmonary hilar vascular, massive parenchymal destruction, or extensive bronchial injury are presented $[16,17]$.

Regardless of indications, pneumonectomy can achieve a high cure rate and low risk of recurrence. However, pneumonectomy is still associated with high postoperative complication rates and severe impairment in respiratory functions. Therefore, post-pneumonectomy patients require several follow-ups and early detection of complications to prevent postoperative mortality. Considering the high risks after a pneumonectomy appropriate patient selection and postoperative management are crucial to improve overall quality of life.

The incidence of pneumonectomy has been decreasing as more parenchymal sparing surgeries have been introduced. Sleeve lobectomy has been proposed as an effective alternative for pneumonectomy. Sleeve lobectomy can significantly improve long-term survival of NSCLC patients without increasing the recurrence rate [18]. However, if mediastinal lymph nodes are present, pneumonectomy may be preferable to sleeve lobectomy due to the lower risk of recurrence [19]. Although pneumonectomy still accounts for $\approx 8 \%$ of major lung resections [20], only a few studies exclusively focus on post-pneumonectomy patients. Post-pneumonectomy patients have severely diminished pulmonary function, which should be taken into consideration in postoperative management. The current study was conducted to provide an overview regarding appropriate postoperative management for post-pneumonectomy patients and to illustrate the limitations of recent studies. The literature search was based on PubMed and SciFinder listings up to 22 February 2021, focusing on manuscripts related to pneumonectomy that was indicated for NSCLC, malignant pleural mesothelioma, and tuberculosis.

\section{Drug Regimen after a Pneumonectomy}

\subsection{Non-Small Cell Lung Cancer}

Lung cancer is a leading cause of death in the United States. Based on statistics from the American Cancer Society, it is estimated that more than 200,000 new patients in the United States will be diagnosed with lung cancer in 2020 [21]. Among lung cancer patients, NSCLC is the most common, accounting for $80-85 \%$ of all lung cancer diagnoses. NSCLC is also the major indication of pneumonectomy when other lung cancer surgeries are not feasible. It is well known that pneumonectomy is an effective surgical option especially in patients with stage II-IIIA NSCLC. For stage I patients, it is controversial whether pneumonectomy should be indicated at this early stage; however, aggressive surgery, such as pneumonectomy, may be recommended in cases where cancerous cells invade the peri-bronchial lymphatic net. After a pneumonectomy, NSCLC patients have severely diminished lung function with a 30-day postoperative mortality rate of $4.0-6.5 \%$ [2,22]. Postoperative quality of life is even lower in female patients and after right-sided pneumonectomy [23]. The prevention of respiratory failure is as important as reducing the risk of cancer recurrence. Therefore, pulmonary conditions of individual patients should be taken into consideration before any decisions are made for adjuvant chemotherapy. Current guidelines from the American Society of Clinical Oncology (ASCO) recommend adjuvant chemotherapy in stage IIA-IIIA patients with NSCLC after complete surgical resections [24]. Although there have been several randomized controlled trials $[25,26]$ and retrospective studies [27-29] that support adjuvant chemotherapy in stage IB, a recent meta-analysis demonstrated that adjuvant chemotherapy did not significantly improve 5-year overall survival and disease-free survival [30]. Addition- 
ally, there was no sufficient evidence to associate adjuvant chemotherapy in stage IB with a lower risk of recurrence [30]. The efficacy of adjuvant chemotherapy on patients with stage IA is uncertain as well, and based on ASCO guidelines, cisplatin-based chemotherapy is not recommended for these patients [24]. With appropriate patient selection and treatments, adjuvant chemotherapy can result in an increased improvement in the 5-year survival rate of up to $4 \%$ [31]. To maximize benefits, physical assessments and communication between patients and health professionals are highly recommended before adjuvant chemotherapy.

In terms of drug regimens, there are a variety of chemotherapeutic agents available depending on countries and institutions. In general, platinum-based drug regimens, mainly cisplatin plus vinorelbine, are administered on days 1,8, and/or 15 every 3 or 4 weeks in an adjuvant setting. Recently, a study combining two meta-analyses reported that there was no significant difference between various chemotherapy regimens [31]. The study implied that platinum-based regimens have the same effect as tegafur-based regimens. However, tegafur-based regimens were mainly administered to Asian populations, whereas platinumbased drug regimens were administered to non-Asian populations [31]. With regard to age, older adult patients are more likely to receive carboplatin-based regimens, especially with paclitaxel [32]. Although there is no absolute superiority between carboplatin and cisplatin, the former is generally more tolerated [32]. It is important to note that older patients benefit from adjuvant chemotherapy as much as younger patients [32]. In terms of increased overall survival and post-operative complications, no significant differences between younger and older adult groups have been seen [32]. This corresponds to a recent study that illustrated that age is not a prognostic factor of adjuvant chemotherapy for NSCLC [33]. Considering that post-pneumonectomy patients have diminished respiratory health and tolerance, these patients may also benefit more from carboplatin than older adult patients do. Appropriate drug regimens should be determined after the evaluation of all the significant factors that may affect post-pneumonectomy patients.

Since pneumonectomy is a relatively uncommon procedure, the majority of studies include lobectomy and segmentectomy patients. Due to the lack of data, the efficacy of adjuvant chemotherapy for post-pneumonectomy patients may be overestimated. A recent study illustrated the efficacy of adjuvant chemotherapy exclusively in postpneumonectomy patients with NSCLC [34]. In the study, three different carboplatin-based drug regimens were administered in three or four cycles: $135-175 \mathrm{mg} / \mathrm{m}^{2}$ taxol on day 1 ; $25 \mathrm{mg} / \mathrm{m}^{2}$ navelbine on days 1 and 8 ; or $1250 \mathrm{mg} / \mathrm{m}^{2}$ gemcitabine on days 1 and 8 [34]. Adjuvant chemotherapy significantly increased overall survival when patients underwent a left-sided pneumonectomy ( $p=0.001$; Figure $1 \mathrm{~A}$ ) or had preoperative FEV1 of equal or higher than 21 ( $p=0.001$; Figure 1C) [34]. Considering that adjuvant chemotherapy can further aggravate pulmonary function, it is reasonable that patients who underwent a right-sided pneumonectomy or who had low FEV1 did not show significant positive outcomes [34]. While age was not a significant factor, patients' respiratory functions played an important role in determining the outcome of adjuvant chemotherapy [34]. Although the retrospective study failed to focus on the effect of individual drug regimens, it is noteworthy that it only included post-pneumonectomy NSCLC patients unlike other previous studies that also examined post-lobectomy and post-segmentectomy patients. 



Figure 1. The outcomes of adjuvant chemotherapy in non-small cell lung cancer (NSCLC) patients depending on pneumonectomy sites and preoperative pulmonary function are shown in Kaplan-Meier actuarial overall survival. (A) Patients after a left-sided pneumonectomy and adjuvant chemotherapy vs. pneumonectomy only. (B) Patients after a right-sided pneumonectomy and adjuvant chemotherapy vs. pneumonectomy only. (C) Patients with preoperative FEV1 $\geq 21$ in adjuvant chemotherapy vs. pneumonectomy only. (D) Patients with preoperative FEV1 < 21 in adjuvant chemotherapy vs. pneumonectomy only. Adapted from [34]. Copyright 2012 Spandidos Publications.

Although adjuvant chemotherapy has proved beneficial, current chemotherapy regimens are still associated with high toxicity. Therefore, several feasibility tests and randomized controlled trials are underway to determine better chemotherapy regimens with reduced toxicity. For current platinum-based regimens, biweekly administration (cisplatin $50 \mathrm{mg} / \mathrm{m}^{2}$ and vinorelbine $25 \mathrm{mg} / \mathrm{m}^{2}$, days 1 and 15, every 4 weeks) or split-dose drug regimen (cisplatin $40 \mathrm{mg} / \mathrm{m}^{2}$ and vinorelbine $25 \mathrm{mg} / \mathrm{m}^{2}$, days 1 and 8 , every 3 weeks) were found to be promising $[35,36]$. However, these attempts to improve standard platinumbased regimens have limitations, and more research has been focusing on other drug regimens, such as epidermal growth factor receptor tyrosine kinase inhibitors (EGFRTKI) [37]. Although the efficacy of EGFR-TKI in advanced NSCLC has been demonstrated, their benefits in the adjuvant setting remain controversial. Previously, an international randomized study failed to show significant improvement in disease-free days among patients with EGFR-expressing stage IB-IIIA NSCLC [38]. However, erlotinib successfully showed improved outcomes in the subgroup of patients with EGFR mutation [38]. Another randomized trial in China demonstrated that gefitinib was superior to vinorelbine plus cisplatin for stage II-IIIA (N1-N2) EGFR-mutated NSCLC patients [39]. In the study, patients with the complete resection of NSCLC achieved reduced toxicity and increased disease-free days after taking gefitinib verses vinorelbine plus cisplatin [39]. Even though some previous studies have insisted that EGFR-TKI should not be used in the adjuvant setting, a recent meta-analysis further assessed the efficacy of adjuvant EGFR-TKI in patients with EGFR-mutated NSCLC [40]. Based on this meta-analysis, postoperative adjuvant EGFR-TKI treatments have a potential to significantly improve disease-free survival and overall survival in patients with stage II-IIIA EGFR-mutated NSCLC [40]. Although the 
meta-analysis stated that it is uncertain if EGFR-TKI would be beneficial to patients with stage I NSCLC [40], a recent randomized controlled trial in patients with stage IB to IIIA EGFR-mutated NSCLC reported a significantly longer disease-free survival at 24 months among patients who received osimertinib vs. placebo ( $89 \%$ vs. 52\%) [41]. In patients with stage II to IIIA EGFR-mutated NSCLC, the disease-free survival at 24 months was $90 \%$ and $44 \%$, respectively [41]. However, without any consideration of EGFR mutation, adjuvant EGFR-TKI did not improve overall survival in general patients with NSCLC [42].

In recent years, immunotherapy has emerged as a promising treatment option in an adjuvant setting for advanced NSCLC patients. Previously, several anti-programmed cell death protein 1 (PD-1) and anti-programmed cell death ligand 1 (PD-L1) antibodies have been approved to be used in patients with NSCLC as monotherapies or in combination with platinum-based chemotherapy. In stage IV NSCLC, pembrolizumab monotherapy and pembrolizumab or atezolizumab in combination with chemotherapy are now the standard first-line therapies. While more clinical trials have evaluated the use of immunotherapy in a neoadjuvant setting rather than adjuvant setting [43], there are some ongoing clinical trials to assess the safety and efficacy of PD-1 and PD-L1 antibodies after lung resection, including atezolizumab (NCT02486718), durvalumab (NCT02273375), nivolumab (NCT02595944), and pembrolizumab (NCT02504372). In various clinical trials, combination therapies with other chemotherapy or radiotherapy are also being evaluated. Although none of them exclusively focused on post-pneumonectomy patients, some trials, including the study of pembrolizumab (NCT02504372), are planned to include post-pneumonectomy patients. Depending on the study population, further research may be needed due to the limited tolerance in post-pneumonectomy patients before assessing generalizability. In terms of toxicity, it has been reported that PD-1 or PD-L1 antibodies are associated with lower risk of grade $3-5$ adverse events compared to chemotherapy (OR 0.45; 95\% CI: 0.38-0.54 for PD-1, HR 0.54; 95\% CI: 0.40-0.72 for PD-L1) [44]. When combined with chemotherapy, PD-1 antibodies showed less frequent grade $3-5$ adverse events than PD-L1 antibodies $(p=0.0302)$ although there was no statistically significant difference as monotherapies [44]. While more studies are needed to determine the optimal drug regimen of immunotherapeutic agents with or without chemotherapy or radiotherapy, PD-1 antibodies may be a better treatment option to be incorporated into post-pneumonectomy management.

In addition to adjuvant chemotherapy, postoperative radiotherapy is another treatment option for patients with NSCLC. This has shown benefits in overall survival, especially for patients with IIIA-N2 NSCLC $[45,46]$. Among patients with stage II-IIIA NSCLC, patients with N2 nodal status showed significantly higher 5-year overall survival when received postoperative radiotherapy vs. patients who did not receive it (34.1\% vs. 27.8\%) [46]. The 5-year overall survival was also higher when patients received radiotherapy in addition to chemotherapy compared to when chemotherapy or radiotherapy were given alone (36.7 vs. 33.6 vs. 23.9, respectively) [46]. Radiation dose is another important factor in determining benefits for patients with N2 nodal status. According to the study, 45-54 Gy had the best outcome in 5-year overall survival (41\% for $45-54 \mathrm{~Gy} ; 33 \%$ for $54-60 \mathrm{~Gy} ; 27 \%$ for greater than $60 \mathrm{~Gy}$ ) [47]. In addition, it was reported that female patients under the age of 60 benefited more from postoperative radiotherapy [47]. However, unlike N2 NSCLC patients, those with N0 or N1 showed a statistically significant reduction in 5-year overall survival after postoperative radiotherapy (10.3\% and $4.6 \%$, respectively) [47]. Therefore, appropriate patient selection and radiation dose are crucial to maximize the benefits.

Although there is sufficient evidence to support postoperative radiotherapy for patients with N2 NSCLC, the aforementioned studies included a large number of postlobectomy patients in their experiments. Recently, several studies have been conducted to evaluate the safety and efficacy of postoperative radiotherapy specifically in postpneumonectomy patients with N2 NSCLC. A recent retrospective study illustrated that adjuvant chemotherapy with postoperative radiotherapy could significantly increase overall survival, disease-free survival, local recurrence-free survival, and distant metastasis-free survival compared to adjuvant chemotherapy alone [48]. In addition, postoperative radio- 
therapy is a valuable treatment option for post-pneumonectomy patients who experience cancer recurrence. In cases of isolated contralateral central intrapulmonary or mediastinal relapse, surgical treatments are generally considered as a prohibitive risk in postpneumonectomy patients. For preoperative stage IIB-IIIB patients, an intensive salvage chemoradiotherapy regimen $\left(30 \mathrm{mg} / \mathrm{m}^{2}\right.$ cisplatin weekly and 60 Gy accelerated radiotherapy) was found to be effective [49]. With or without chemotherapy, post-pneumonectomy patients who received radiotherapy for relapse are associated with substantially lower 90day mortality compared to patients who did not receive radiotherapy $(4.9 \%$ vs. $31.9 \%)$ [50]. While radiotherapy may be considered a valuable alternative to surgical treatment or adjuvant chemotherapy, radiation toxicity should be taken into consideration. To minimize toxicity, a growing number of studies support the use of stereotactic body radiotherapy over conventional or hypofractionated radiotherapy [51-53]. Although it is still possible that stereotactic body radiotherapy will further aggravate pulmonary function, the toxicity is generally acceptable considering its benefit for post-pneumonectomy patients. With careful monitoring, radiotherapy can be beneficial in combination with adjuvant chemotherapy or as a concurrent chemoradiotherapy for relapse.

\subsection{Malignant Pleural Mesothelioma}

Malignant pleural mesothelioma (MPM) is a relatively rare but aggressive type of cancer affecting the lining of the lung. In the United States, approximately 3000 people are newly diagnosed with mesothelioma each year, with a slightly higher incidence in men [54]. Although the number of new cases has been decreasing, the overall 5-year survival rate of mesothelioma patients is only $10 \%$ [54]. The poor prognosis is mainly due to the difficulty of diagnosing it in the early stages. In terms of curative treatments, there are two types of surgery commonly available for MPM patients: pleurectomy/decortication (P/D) and extrapleural pneumonectomy (EPP). While P/D spares the lung by removing only parietal and/or visceral pleura, EPP is the resection of the lung, parietal pleura, pericardium, and diaphragm. It has been reported that EPP is associated with higher perioperative mortality, lower quality of life, and lower tolerance in adjuvant chemotherapy compared to P/D [55]. However, the recurrence rate of EPP is two times lower than P/D [55], and the 5-year survival rate is not significantly different between the two [56]. For many years, $\mathrm{P} / \mathrm{D}$ has been conducted in early stages to save the lung. Although EPP has usually been reserved for advanced stages of MPM, the database from International Association for the Study of Lung Cancer (IASLC) supports utilizing EPP over P/D in patients with stage I MPM [57]. Unlike other studies or current clinical practice, the data show that patients with stage I MPM can benefit more from EPP compared to P/D in terms of overall survival (40 months vs. 23 months) [57]. Considering that MPM is associated with high heterogeneity and various mutations, individual preoperative assessment and proper surgical decision-making are crucial in patients with MPM.

MPM patients often undergo multimodality therapy, which consists of chemotherapy and/or radiotherapy in combination with surgery [58]. A common curative treatment, trimodality therapy, involves induction or adjuvant chemotherapy and EPP, followed by adjuvant radiotherapy. However, the timing of chemotherapy is still controversial, with debates between induction (or neoadjuvant) chemotherapy and adjuvant chemotherapy [58] A recent systemic review of overall trimodality therapy, including induction/adjuvant chemotherapy, EPP, and adjuvant radiotherapy, reported a median survival of 12.8-46.9 months [59]. Perioperative morbidity is quite problematic (50-82.6\%), with disease-free survival of 10-16.3 months [59]. For patients who received induction chemotherapy as in trimodality therapy, the median overall survival was 16.8-25.5 months on intention-to-treat analysis [59]. Another study involving induction chemotherapy had a 2-year survival rate of $61.2 \%$ after completing the trimodality therapy [60]. For patients who received adjuvant chemotherapy instead, the median overall survival was 19-24 months, with one study reporting 46.9 months [59]. Although adjuvant chemotherapy has been used more commonly in the past, induction chemotherapy plus adjuvant radiotherapy is currently 
preferred, since a high dosage of chemotherapy can be more safely administered before surgery. Due to the toxicity of chemotherapy, it is relatively difficult to administer chemoradiotherapy in the adjuvant setting [61]. However, adjuvant chemotherapy can overcome some disadvantages of induction chemotherapy, such as the difficulty of finding a proper dissection plane during surgery or the increased risk of residual tumor regrowth [58]. Since there is no single standard multimodality treatment that can be applied for all MPM patients, treatment options should be determined by considering individual functional status, pathological stages, the resectability of the tumor, and age [62].

Drug regimens for post-EPP patients have been changed. Previously, platinum-based regimens, especially with gemcitabine were popular in adjuvant chemotherapy. Cisplatin $\left(100 \mathrm{mg} / \mathrm{m}^{2}\right)$ on day 15 plus gemcitabine $\left(1000 \mathrm{mg} / \mathrm{m}^{2}\right)$ on days 1,8 , and 15 were commonly given to MPM patients every 4 weeks [63]. The adjuvant chemotherapy was generally begun between 4 and 10 weeks after EPP depending on individual recovery and often suspended due to toxicity [63]. The same drug regime with a different dose and schedule was also used (cisplatin $75 \mathrm{mg} / \mathrm{m}^{2}$ on day 1 plus gemcitabine $1250 \mathrm{mg} / \mathrm{m}^{2}$ on day 1 and 8 , every three weeks) [64]. Recently, folate analogues were found to have better cytotoxic activities [65]. Cisplatin with pemetrexed has become a more standard chemotherapy regimen in MPM patients [65]. In addition to the cisplatin with pemetrexed, cyanocobalamin and folic acid may be recommended in MPM patients to prevent pemetrexed-related adverse events [65]. Cyanocobalamin $1000 \mathrm{mg}$ every nine hours with daily folic acid $400 \mathrm{mg}$ was found to be effective in reducing the risk of nausea, vomiting, fever, mucositis, and diarrhea in patients who received pemetrexed [65]. In older adult patients with previous chemotherapy-related toxicity experiences, carboplatin may be administered instead of cisplatin [65]. Although carboplatin plus pemetrexed is also associated with chemotherapyrelated toxicity, the drug regimen has the potential to improve the overall toxicity profile for selective patients [65]. However, before any recommendation, individual physical status should be considered in MPM patients to maximize the benefit of adjuvant chemotherapy.

Although cisplatin with pemetrexed is now well known as the standard chemotherapy, only a few studies have focused on the efficacy of the drug regimen exclusively in post-EPP patients. More supportive evidence is available for post-P/D patients and preEPP patients. Among clinical trials for post-EPP patients with adjuvant cisplatin plus pemetrexed [64,66-68], many patients received $75 \mathrm{mg} / \mathrm{m}^{2}$ cisplatin with $500 \mathrm{mg} / \mathrm{m}^{2}$ pemetrexed on day 1 every 3 weeks in combination with radiotherapy $[64,66]$. The toxicity of this combination therapy was relatively low and well tolerated. Another clinical trial on post-EPP patients with adjuvant cisplatin plus pemetrexed accounted for $44.6 \%$ of the total population studied [67]. The trial resulted in 3-year locoregional control of $90 \%$ and overall survival of $60 \%$ [67]. However, the study was mainly focused on the effect of adjuvant radiotherapy and failed to show the influence of adjuvant chemotherapy. In addition, a retrospective study assessed the overall outcomes of adjuvant cisplatinbased drug combination with or without radiotherapy [68]. Cisplatin, pemetrexed, and vinorelbine were administered after EPP (15 patients with radiotherapy and 14 patients without radiotherapy) [68]. The postoperative complication rates were higher when the adjuvant chemotherapy was administered with radiotherapy compared to the adjuvant chemotherapy alone (53\% vs. 36\%) [68]. However, due to the small number of MPM patients, the study was unable to assess the effect of individual drug regimen [68]. Based on a systemic review, it was reported that only 751 patients were identified to have adjuvant chemotherapy after either P/D or EPP among studies published between 2007 and 2015 [58]. No single study has been conducted exclusively focusing on adjuvant cisplatin plus pemetrexed regimen after EPP. Due to the rare incidence of MPM, there are limitations in evaluating the efficacy of specific drug regimens after EPP. In addition, current studies of multimodality therapy have been focused on overall outcomes of all combined treatments and not necessarily on the efficacy of individual therapies. The benefits of current adjuvant chemotherapy may have been over or underestimated due to the presence of adjuvant radiotherapy. 
There are many ongoing clinical trials evaluating better drug regimens for MPM patients. Targeted chemotherapy seems to be promising, since current cytotoxic chemotherapy has limitations, such as improvement in overall survival or response rates [69]. However, no tyrosine kinase inhibitor (TKI) has been approved for use for MPM patients in the adjuvant setting. Although the majority of MPM patients exhibit EGFR overexpression [69], EGFR-targeted therapies require further assessment before widespread use. A phase II clinical study evaluated the efficacy of gefitinib with MPM patients [70]. The result was poor with a median overall survival of only 6.8 months [70]. In addition, the study implied that the EGFR overexpression may not be the predictor of better response to TKI [70]. Another trial with erlotinib revealed similar results with median overall survival of 10 months [69]. In the study, the 1-year survival rate was $43 \%$, and median progressionfree survival was 2 months despite the EGFR overexpression [69]. However, the study suggested the activated phosphatidylinositol 3-kinase/Akt pathway as a potential target for further research [69]. In MPM patients who previously received one chemotherapy regimen, the combination of erlotinib and bevacizumab has been tested in a phase II clinical study. The median survival was poor (5.8 months), and only half of the patients achieved stability for two cycles of chemotherapy [71]. In addition, two studies have examined TKIs targeting a platelet-derived growth factor, specifically imatinib [72] and dasatinib [73]. However, neither of these were found to be effective in MPM patients [72,73].

While past approaches to targeted chemotherapy did not demonstrate beneficial effects, recent studies have looked at adding a specific TKI to the standard drug regimen of cisplatin plus pemetrexed. The addition of bevacizumab to the standard regimen was associated with an increase of overall survival compared to the standard drug regimen without bevacizumab (18.8 months vs. 16.1 months) [74]. Progression-free survival was also higher in bevacizumab with the standard drug regimen (9.2 months vs. 7.3 months) [74]. In a phase II clinical trial, nintedanib displayed clinically meaningful results in progressionfree survival in combination with cisplatin plus pemetrexed [75], although the benefit was less pronounced in a recent phase III clinical study [76]. Cediranib was another option for the triplet regimen, combined with cisplatin and pemetrexed. There was no significant outcome in overall survival, but the triplet regimen increased progression-free survival from 5.6 to 6.9 months [77]. The main issue in the triplet regimes is the higher toxicity compared to the standard regimen. Patients who received bevacizumab with the standard regimen experienced more grade 3 or higher hypertension and thrombotic events compared to patients with cisplatin plus pemetrexed only ( $23 \%$ vs. $0 \% ; 6 \%$ vs. $1 \%$, respectively) [74]. For cediranib, $69 \%$ of patients who received the drug had grade 3 or higher toxicities versus $57 \%$ of patients with standard drug regimen [77], while $29 \%$ of patients discontinued cediranib due to the toxicity during the trial [77]. While the triplet regimens still have a potential to be used in MPM patients, the feasibility of targeted chemotherapy in an adjuvant setting has not been fully determined. Post-EPP patients are generally less tolerant to chemotherapy and hence require a safer and less toxic drug regimen. Considering the high toxicity, targeted chemotherapy may not be appropriate in MPM patients who underwent EPP, although a definite conclusion cannot be drawn at this point.

In patients with MPM that has progressed after first-line platinum-based chemotherapy, immunotherapy has been proposed as a promising treatment option. Several PD-1 or PD-L1 antibodies, such as pembrolizumab, nivolumab, and avelumab, have been evaluated as monotherapy or in combination with anti-cytotoxic T lymphocyte antigen 4 (CTLA-4) inhibitors. The exact role of PD-1 or PD-L1 expression as a biomarker is unclear, but several trials displayed disease control rates up to $72 \%$ for pembrolizumab [78,79], 68\% for nivolumab [80,81], and 58\% for avelumab [82] with acceptable safety profiles. Although pembrolizumab did not result in better progression-free survival or overall survival compared to standard chemotherapy in the first randomized controlled trial [83], PD-1 or PD-L1 antibodies were generally well-tolerated with encouraging clinical activities in small studies [78-82]. The mean overall survival for pembrolizumab, nivolumab, and avelumab 
was 7.2-18.0 months [78,79], 11.8-17.3 months [80,81], and 10.7 months [82], respectively. When nivolumab was administered with ipilimumab, a CTLA-4 inhibitor, the median progression-free survival was 6.2 months with overall survival of $64 \%$ at 12 months [84]. This result corresponds with a randomized controlled phase 2 trial, where the same combination resulted in median progression-free survival of 6.2 months and overall survival of $58 \%$ [85]. Similar results were observed durvalumab plus tremelimumab combination treatment, with median progression-free survival of 8.0 months and mean overall survival of 16.6 months [86]. However, there has been no study conducted to evaluate the feasibility of immunotherapy in an adjuvant setting. Unlike targeted chemotherapy, patients who underwent immunotherapy generally report less toxicity compared to standard chemotherapy. Although well-established randomized controlled trials with a large sample size are needed to further demonstrate the efficacy and safety, immunotherapy has the potential to be developed as a treatment option for post-EPP patients considering the safety profiles.

In post-EPP patients with MPM, recurrence rates remain problematic. According to a large cohort study, the recurrence rate after EPP was 75\% (118/158), with median survival of 15 months [87]. The most frequent site of recurrence was the ipsilateral hemithorax or mediastinum, which was followed by the abdomen and the contralateral hemithorax (Figure 2) [87]. This result corresponds to a more recent retrospective analysis, which reported $78 \%$ of the recurrence rate among 136 patients after induction chemotherapy and EPP [88]. In this study, second-line treatments were given to 78 patients, consisting of $71 \%$ of chemotherapy, $23 \%$ of radiotherapy, and $21 \%$ of additional surgery [88]. Eleven patients $(14 \%)$ had a combination of two different therapies, while the rest $(86 \%)$ received a single therapy [88]. The chemotherapy regimens were most likely cisplatin (85\%) and pemetrexed $(79 \%)$ [88]. Patients who received second-line treatments achieved significantly longer survival rates compared to patients who did not receive additional treatments (10 months vs. 2 months) [88]. Adjuvant radiotherapy was found to be effective in decreasing the risk of recurrence after EPP, but it could not improve overall survival due to its limited efficacy in distant metastasis [88]. Another recent retrospective analysis evaluated the efficacy of additional chemotherapy in patients with relapsed MPM after previous multimodality therapy [89]. Patients had received preoperative hemithoracic radiation, EPP, and adjuvant chemotherapy before the recurrence [89]. Among 42 patients who were diagnosed with relapsed diseases, only 15 patients underwent systemic therapy [89]. The majority of patients received platinum and antifolate doublet, but approximately half of these patients halted the treatment due to chemotherapy-related toxicity [89]. Although only $36 \%$ of total patients were treated as planned, resulting in poor median overall survival of 4.8 months, this study illustrated that patients with Eastern Cooperative Oncology Group performance status $\geq 2$, disease-free interval $<1$ year, and hemoglobin $\leq 110 \mathrm{~g} / \mathrm{L}$ were at a higher risk in systemic therapy [89]. While the most appropriate management of relapsed MPM remains controversial, identifying ideal candidates for further treatments is crucial to improve the poor prognosis after recurrence. 


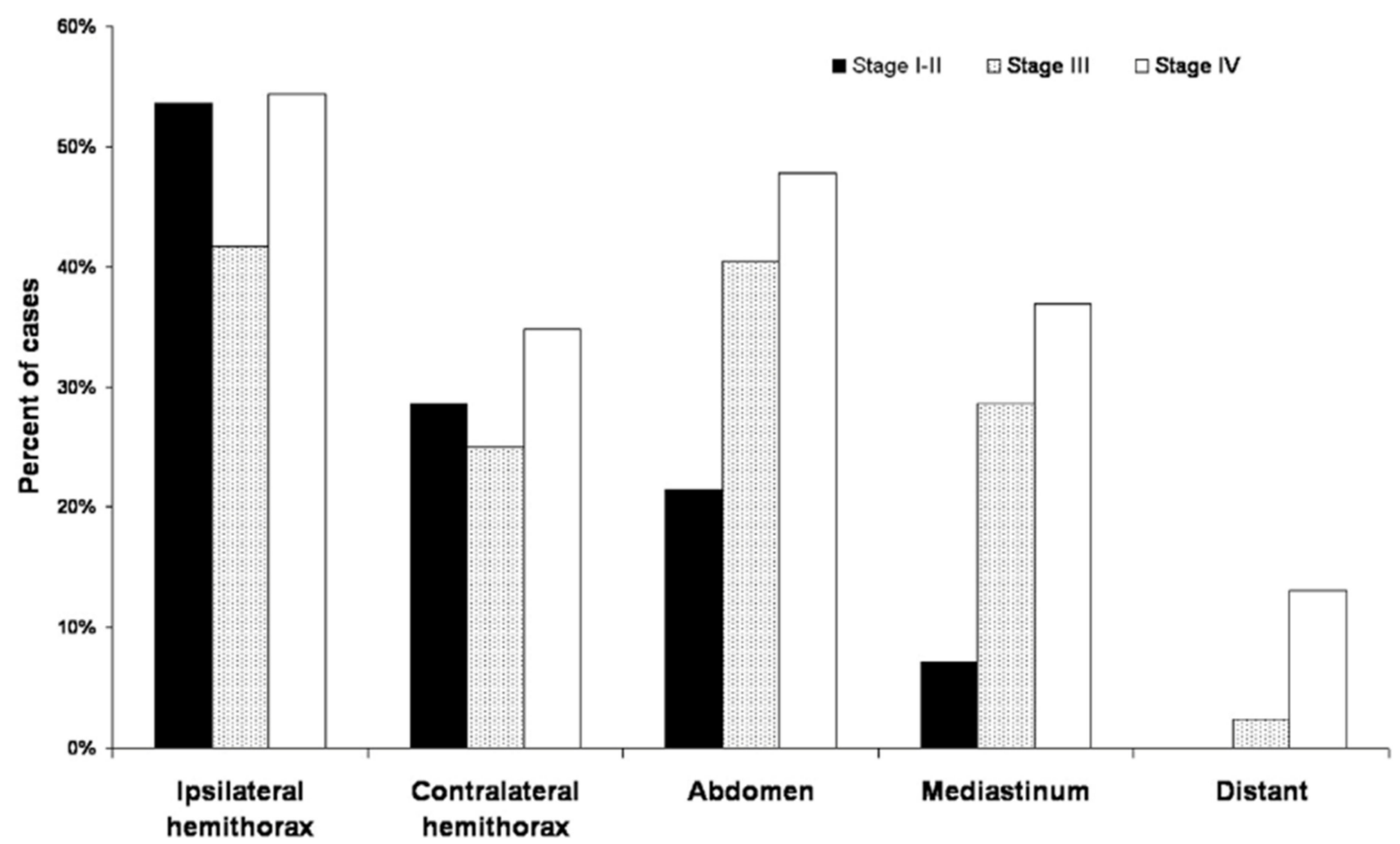

Figure 2. Pattern of first recurrence sites in post-EPP patients $(n=158)$ based on the American Joint Committee on Cancer stage. Adapted from ref [87]. Copyright 2015 The American Association for Thoracic Surgery.

\subsection{Tuberculosis}

Tuberculosis (TB) causes 1.5 million deaths each year, making it the leading cause of death from infectious disease worldwide [90]. According to a recent World Health Organization (WHO) report, approximately one-quarter of the global population can develop TB from the bacillus Mycobacterium tuberculosis infection, although the lifetime risk is less than $10 \%$ [91]. Currently in the United States, there are two to three people infected with TB per 100,000 persons [92]. The incidence of TB has been decreasing in the United States, but the rate of the decline has slowed (6.4\% per year during 2007-2012 vs. $2.1 \%$ per year during 2012-2019) [92]. Due to the advance in medical treatments, lung surgeries for TB have become less popular. However, it is estimated that $\approx 5 \%$ of TB patients may still require surgeries as an induction therapy or an adjuvant therapy in addition to medical treatments [93]. Pulmonary resections for TB are mainly performed for elective indications, such as in cases of multidrug-resistant tuberculosis (MDR-TB) or extensively drug-resistant tuberculosis (XDR-TB). Less commonly, TB patients may undergo pulmonary resections due to TB-related complications/sequelae or emergency indications such as hemoptysis [94]. According to a recent study, radical pulmonary resections for TB can achieve a high success rate (79-100\%) [94]. In terms of surgical decision-making for $\mathrm{TB}$, less invasive surgeries are preferred, but pneumonectomy and pleuropneumonectomy still account for $12-15 \%$ of total lung resections for TB [94]. The major indication for pneumonectomy in TB patients is a tuberculosis-destroyed lung and widespread irreversible lesions [94]. Based on a recent prospective study, the complication rate of overall pneumonectomy cases for TB was 30.8\% [95]. Postoperative morbidity increased in MDR-TB and XDR-TB patients, but the TB patients in the study achieved a $100 \%$ success rate with pneumonectomy [95]. Emergency pneumonectomy for hemoptysis is relatively rare, but it is associated with a significantly higher risk of complications compared to emergency lobectomy ( $72 \%$ vs. $52 \%$ ) [94]. To decrease postoperative morbidity, alternatives to pneumonectomy, such as combined and rare polysegmental resection, may be considered for TB patients. 
The majority of TB patients can be successfully treated by receiving a combination of isoniazid, rifampicin, pyrazinamide, and ethambutol. In general, drug-susceptible TB does not require a radical pulmonary surgery unless the patient has a severely destroyed lung. However, inappropriate management of TB historically has resulted in the emergence of drug-resistant TB. For selective drug-resistant TB patients, pulmonary resections are a valuable option over medical therapy. Based on the report from the $\mathrm{WHO}$, the overall success rate of treatments for MDR-TB and XDR-TB are $\approx 60 \%$ and $\approx 40 \%$, respectively [91]. Approximately 500,000 new cases of MDR-TB are emerging each year [91], and standard medical treatments for drug-susceptible TB patients are inadequate in these drug-resistant TB patients. Although the most effective standard treatment has not been fully determined for these patients, pulmonary resections are highly recommended in addition to medical treatments. According to a study that compared outcomes between surgical groups and non-surgical groups in treating MDR-TB, the successful outcome rates were $81.9 \%$ vs. $59.7 \%$, respectively [96]. An observational cohort also demonstrated the important role of pulmonary resections in treatments of MDR-TB and XDR-TB. Among 75 patients (51 MDR and 24 XDR) who underwent adjuvant surgery, the rates of favorable outcomes were $90 \%$ and $67 \%$ [97]. Another study with $72 \mathrm{~TB}$ patients (46 MDR and $26 \mathrm{XDR}$ ) reported the overall favorable outcome rate of $90 \%$ after pulmonary resections, with no significant difference between MDR-TB and XDR-TB (93\% vs. 85\%) [98]. Although better success is achieved with surgery, it is an invasive procedure. Therefore, appropriate patient selection and preoperative assessment is necessary in surgical decision-making.

Adjuvant chemotherapy after pulmonary resections is highly recommended in drugresistant TB patients. It is well known that postoperative anti-TB chemotherapy can reduce the risk of relapses from persistent foci [94]. To date, there has been no study exclusively focused on post-pneumonectomy TB patients. However, several studies including a great portion of pneumonectomy patients have reported successful outcomes of adjuvant anti-TB chemotherapy [10,99-104]. TB patients were considered as cured when acid-fast bacilli (AFB) negative sputum conversion was produced throughout 18 months of treatments. All of these studies achieved at least $90 \%$ of AFB negative sputum conversion/overall cure rates with appropriate chemotherapy after pulmonary resection [10,99-104]. Adjuvant anti-TB chemotherapy usually lasted for 6 months, with the median duration of 18 months [10,99,100,103]. After the combination therapy of pulmonary resections and postoperative medical treatments, the majority of studies reported zero [99,103] or only a few $(n=1-3)[10,100-102]$ cases of relapse with acceptable morbidity and mortality. In terms of drug regimen, there is no specific drug combination that can be used in all TB patients after a surgery. Individual drug regimens are determined based upon the results of drug susceptibility tests and, if possible, they consist of a variety of anti-TB drugs to prevent further drug resistance. Patients who underwent a surgery often resume their preoperative drug regimens if no correction is necessary. In general, common first-line drug regimens, such as isoniazid, rifampin, pyrazinamide, ethambutol, and streptomycin, are preferred without a significant difference between pre- and post-operative treatments.

Due to the complexity and toxicity of current anti-TB chemotherapy, many studies have aimed to develop a new TB drug regimen. To date, there are three novel drugs recently introduced for anti-TB treatments: bedaquiline, delamanid, and pretomanid. Bedaquiline is the first drug approved by the FDA to be used against MDR-TB in decades [105]. It is an adenosine triphosphate synthase blocker, which can reduce the risk of adverse effects in TB patients by selectively working against Mycobacterium's ATP synthase [105]. According to a systematic review, bedaquiline with a standard drug regimen for MDR-TB can significantly decrease the length of treatment compared to placebo [106]. However, bedaquiline should only be used when more effective treatments are not feasible. While the labeled regimen is a daily dose of $400 \mathrm{mg}$ for 14 days followed by $200 \mathrm{mg}$ twice a week for 22 weeks, a recent study proposed a simpler drug regimen of a daily dose of $200 \mathrm{mg}$ for 2 months followed by $100 \mathrm{mg}$ daily for the remaining 12 weeks [107]. It is estimated that the proposed drug regimen has a similar safety and efficacy profile but more benefits available in terms of 
adherence [107]. Delamanid is another promising anti-TB drug that is meant to be used in combination with other anti-TB drugs. It is a mycolic acid biosynthesis inhibitor against Mycobacterium tuberculosis. Based on a phase IIA randomized controlled trial, there was no statistically significant difference among 100, 200, 300, and $400 \mathrm{mg}$ of daily dose in terms of early bactericidal activity [108]. In terms of sputum decline, 200 and $300 \mathrm{mg}$ showed a better outcome compared to $100 \mathrm{mg}$ [108]. While all of the dosages are safe and well tolerated, on day 3, patients can achieve a significant increase in bactericidal activity, which is similar to a standard drug combination, isoniazid, rifampicin, pyrazinamide, and ethambutol [108]. Pretomanid was recently approved to be used in combination with bedaquiline and linezolid against MDR-TB and XDR-TB. It was reported that this drug combination achieved $90 \%$ favorable outcomes among 109 highly drug-resistant infected patients [109]. Linezolid-induced toxicity, such as peripheral neuropathy or myelosuppression, was common, but these toxic effects could be successfully managed by reducing the dose [109]. Although all of the three novel drugs can be used in drug-resistant $\mathrm{TB}$, their efficacies in adjuvant settings remain unclear. Considering that post-operative drug regimens for $\mathrm{TB}$ are highly individualized, the development of novel drug regimens may benefit post-pneumonectomy patients by providing more treatment options.

When a lung is totally destroyed, surgery should be performed to prevent complications, such as recurrent infections and frequent hospitalizations [110]. Unlike drugresistant $\mathrm{TB}$, when pneumonectomy is indicated to remove a TB-destroyed lung, adjuvant chemotherapy may not be required. Unless patients are infected with active drug-resistant $\mathrm{TB}$, patients with a TB-destroyed lung generally achieve satisfactory outcomes with preoperative anti-TB chemotherapy and careful operation of pneumonectomy [111]. According to a retrospective study of 172 cases of TB-destroyed lungs, the clinical cure rate was $91.9 \%$ after a pneumonectomy following induction chemotherapy [111]. However, if necessary, patients can resume their previous anti-tuberculosis chemotherapies after surgery based on their practitioner's recommendation. For patients with a TB-destroyed lung, the main indication of pneumonectomy is the presence of severe pleural adhesions [111]. The lung lesions should be removed to reduce the risk of complications, such as postoperative empyema [111]. Pneumonectomy for a TB-destroyed lung is rare in children, but it may become necessary when the destroyed lung irreversibly changes the lung parenchyma or causes severe acute/chronic complications [110]. After a lung removal, children are more likely to experience compensatory lung growth, which eventually results in improved exercise capacity and tolerance [110]. However, pneumonectomy for a TB-destroyed lung is associated with high postoperative complication rates [12,13]. Although pneumonectomy for a destroyed lung can achieve high long-term survival [12,13], to improve quality of life, the management of postoperative complications is crucial. Especially for patients with low predicted postoperative FEV1, several follow-ups are highly recommended for the early detection of postoperative complications [12].

\subsection{Respiratory Health}

Post-pneumonectomy patients are known to have severely impaired respiratory health. Based on spirometry tests, both static and dynamic lung volumes, such as FEV1, FVC, and RV, significantly decreased in patients who survived more than a year after a pneumonectomy [112]. However, there is no single drug to improve overall pulmonary function in post-pneumonectomy patients. As these patients are susceptible to postoperative complications and respiratory failure, conservative management of the remaining lung may not be adequate to improve quality of life. Present studies have been aiming to develop treatments that can actively improve pulmonary function after a pneumonectomy [113-125]. Among these studies, post-pneumonectomy compensatory lung growth seems to be especially promising. Pneumonectomy can stimulate the active growth of a remaining lung as compensation for the removed lung portion [113]. If compensatory lung growth can be stimulated by a pharmaceutical intervention, it would result in the development of lung regenerative therapy, which can benefit patients with diminished pulmonary 
function [113]. While there is no drug yet approved to be used in post-pneumonectomy patients for this purpose, many animal experiments are underway to identify effective pharmaceutical treatments that induce compensatory lung growth [113].

Lung growth involves numerous growth factors to form a properly functioning complex structure. To stimulate compensatory lung growth, the administration of exogenous growth factors or the recruitment of endogenous growth factors are considered in several studies. Epidermal growth factor (EGF) modulates epithelial maturation and regeneration, which is involved in both prenatal and postnatal lung development [114]. In adult male rats, exogenous epidermal growth factor was found to stimulate compensatory lung growth [114]. When treated with EGF, these rats achieved a higher lung volume and weight index, with no significant change in the alveolar surface density [114]. Heparin-binding epidermal growth factor (HB-EGF) is a type of EGF consisting of EGF-like domain with a heparin-binding site [114]. HB-EGF is observed in diverse organs and has potential to be used in stimulating alveolar regeneration after pneumonectomy [115]. It is released from the activation of vascular endothelial growth factor receptor 2 (VEGFR2) and promotes tissue repair and regeneration [115]. Although there are remaining issues to be solved before its clinical use, such as the development of a proper delivery system, therapeutic strategies utilizing HB-EGF sound promising. Vascular endothelial growth factor (VEGF) is another important factor in blood formation during lung generation [116]. When a VEGF neutralizing antibody was administered to post-pneumonectomy mice, compensatory lung growth was significantly diminished [116]. The study suggested that VEGF supported compensatory lung growth via the mobilization and recruitment of progenitor cells to the lung [116]. Another study also illustrated that VEGF facilitated compensatory lung growth in post-pneumonectomy mice [117]. VEGF decreased the time for complete compensatory lung growth from 8 to 10 days to 4 days, with no significant morphometric differences [117]. In addition, keratinocyte growth factor and hepatocyte growth factor were also found to stimulate post-pneumonectomy compensatory lung growth in murine models $[118,119]$. While all of these growth factors have the potential to be used in postpneumonectomy treatments, the downregulation of growth factor receptors should be taken into consideration when developing growth factors-related therapeutic strategies.

There are two novel methods that potentially stimulate compensatory lung growth after a pneumonectomy: the administration of VEGF receptor 1 (VEGFR1) and erythropoietin (EPO). A recent study reported that the systemic administration of VEGFR1, a VEGF inhibitor, stimulated angiogenesis and increased lung volume of mice [120]. VEGFR1 increased the level of VEGF and VEGFR2 in the lung, enhancing endothelial proliferation and pulmonary surfactant production [120]. Although it cannot be easily applied to humans, VEGFR1 was effective in stimulating compensatory lung growth in mice at the dose of $20 \mu \mathrm{g} / \mathrm{kg}$ [120]. Meanwhile, EPO was also found to promote endothelial cells growth and to induce angiogenesis [121]. During compensatory lung growth, the upregulation of EPO has been reported in post-pneumonectomy canines; however, the efficacy of exogenous EPO inhalation was unclear [121]. In a recent study, post-pneumonectomy adult canines received weekly human EPO-containing nanoparticles for 16 weeks [121]. EPO selectively promoted alveolar angiogenesis in the remaining lobes [121]. However, EPO administration did not induce the extravascular tissue growth of a whole lung, which resulted in a discrepancy between structure and function of the tissue [121].

Thyroid transcription factor 1 (TTF-1) is involved in the early phase of compensatory lung growth in adult mice [122]. When TTF-1 was silenced by small inhibitory RNA, postpneumonectomy compensatory lung growth was delayed [122]. The combination of dexamethasone, 8-bromo- $3^{\prime}-5^{\prime}$-cyclic adenosine monophosphate, and isobutylmethylxanthine (DCI) was found to elevate TTF-1 expression in epithelial cells of the lung [123]. In adult male mice, airway administration of DCI facilitated the initiation of post-pneumonectomy compensatory lung growth [123]. Based on morphological analysis, DCI increased the number of alveoli and decreased the size of alveoli [123]. This resulted in an increase of surface area of the alveoli [123]. Once the compensatory lung growth is stimulated, 
its maintenance is less important. Therefore, DCI may not be required for a prolonged time [123]. In addition, DCI administration was not effective without previous pneumonectomy experience [123]. Therefore, its clinical use may be limited to compensatory lung growth. Although further assessment is necessary before the use of DCI in postpneumonectomy patients will be authorized, DCI administration seems to be promising to potentially improve the function of the remaining lung.

Post-pneumonectomy therapies involving immune cells are also under development to stimulate compensatory lung growth. A recent study demonstrated that recruited monocytes and type 2 immunity can enhance compensatory lung growth after a pneumonectomy [124]. For proper compensatory growth of the remaining lung, the recruitment of monocytes and interleukin 4 receptor a-expressing leucocytes are needed (Figure 3) [124]. According to the study, these monocytes and macrophages may play an important role in modulating cell proliferation and differentiation during compensatory lung growth [124]. In addition, type 2 innate lymphoid cells were proposed as a source of IL-13, which can induce the polarization of macrophage and further stimulate compensatory lung growth [124]. Soluble platelet-rich plasma extract was also found to be effective in enhancing compensatory lung growth. This plasma extract contains numerous factors that stimulate angiogenesis including angiopoietin-1 [125]. In animal experiments with mice, platelet-rich plasma extracts successfully activated angiogenic factor receptors in endothelial cells and facilitated compensatory lung growth [125]. Although none of the aforementioned studies were conducted on humans, these therapeutic interventions have potential as effective strategies for compensatory lung growth in post-pneumonectomy patients.

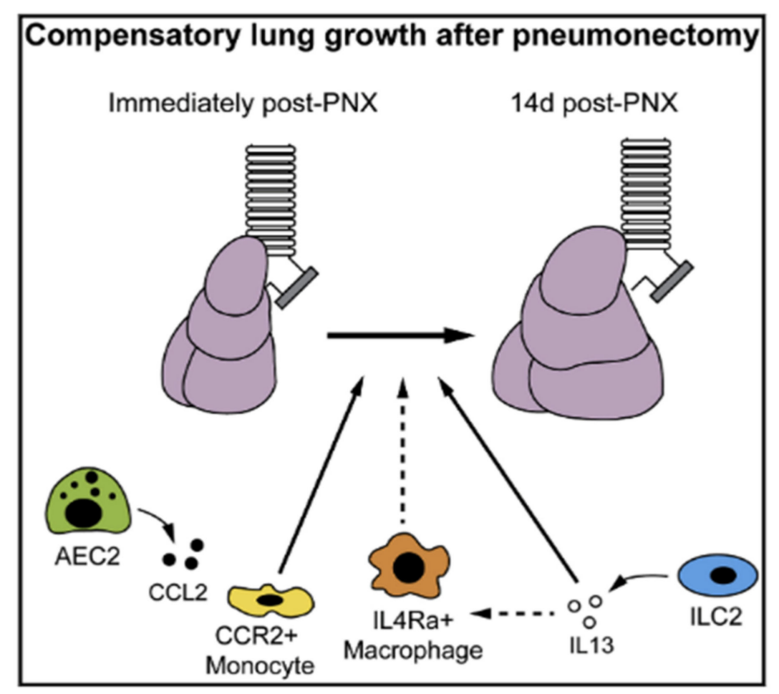

Figure 3. Graphical abstract of post-pneumonectomy compensatory lung growth in potential immunomodulatory therapies. (AEC2: Type 2 alveolar epithelial cells; CCL2: C-C Motif Chemokine Ligand 2; CCR: C-C chemokine receptor 2; IL4Ra: interleukin 4 receptor; IL13: Interleukin 13; ILC2: Type 2 innate lymphoid cells). Adapted from [124]. Copyright 2017 Cell Press.

In addition to compensatory lung growth, some non-pharmaceutical treatment options have been investigated to improve respiratory health in post-pneumonectomy patients. Physiotherapy programs are common both in preoperative and postoperative treatments. It is well known that post-pneumonectomy patients have severely diminished exercise capacity compared to preoperative physical condition. According to a randomized controlled trial, high-intensity exercise training is beneficial in terms of improved peak oxygen uptake, muscular strength, total muscle mass, and quality of life in postoperative lung cancer patients [126]. Current physiotherapy programs are highly heterogenous because these programs are individualized based on patients' physical status and needs. Some common therapeutic targets are respiratory muscle training, bronchial hygiene, and exercise training [127]. In general, physiotherapies are aiming to prevent postoperative complications 
and decrease the length of hospital stay [127]. Although the efficacy of physiotherapy specifically in post-pneumonectomy patients should be further evaluated, postoperative patients are encouraged to maintain exercise training after lung surgery [127].

\section{Conclusions}

Pneumonectomy is a procedure that may become necessary for both malignant and benign diseases. Regardless of indications, individual outcomes have been substantially improved not only due to technical advance but also via appropriate drug regimens after the invasive surgery. While it is well known that post-pneumonectomy patients can significantly benefit from postoperative treatments, many clinical trials have been aiming to further demonstrate the efficacy of adjuvant chemotherapy. Conventional approaches include the improvement of currently available drug regimens, whereas many ongoing trials are aimed at developing novel drug regimens for post-pneumonectomy patients. Despite the benefits brought by pneumonectomy, postoperative complications are still problematic. Atrial fibrillation (AF) is the most common complication $[23,128]$, whereas bronchopleural fistula (BPF) and postpneumonectomy syndrome (PPS) are relatively rare but can be life-threatening [6-8,129]. There are several pharmaceutical drug regimens to treat postoperative AF. In general, amiodarone, beta-blockers, diltiazem, and/or digoxin are commonly used for these patients. To prevent BPF, the coverage of bronchial stump is highly recommended, especially for patients who underwent a right-sided pneumonectomy and experienced adjuvant chemotherapy [129]. PPS is a mediastinal shift toward the site of the excised lung, which causes significant compression in the central airway. Similar to BPF, patients who experience PPS undergo surgical correction to reposition the mediastinum. Although patients who underwent a right-sided pneumonectomy are perceived to be at a higher risk of these complications, BPF and PPS can occur both after right- and left-sided pneumonectomy $[9,130]$. Management of these complications has been an essential task to improve the postoperative quality of life in pneumonectomy patients. Overall, it is important to identify high-risk patients though preoperative physical assessments and to monitor these patients for early detection of the complications.

Funding: This research received no external funding.

Institutional Review Board Statement: Not applicable.

Informed Consent Statement: Not applicable.

Data Availability Statement: Not applicable.

Acknowledgments: The authors wish to thank the School of Pharmacy at the Massachusetts College of Pharmacy and Health Sciences University for financial support of this project.

Conflicts of Interest: The authors declare no conflict of interest.

\section{References}

1. Gu, C.; Wang, R.; Pan, X.; Huang, Q.; Luo, J.; Zheng, J.; Wang, Y.; Shi, J.; Chen, H. Comprehensive study of prognostic risk factors of patients underwent pneumonectomy. J. Cancer 2017, 8, 2097-2103. [CrossRef] [PubMed]

2. Dogru, M.V.; Sezen, C.B.; Aker, C.; Girgin, O.; Kilimci, U.; Erduhan, S.; Metin, M. Evaluation of factors affecting morbidity and mortality in pneumonectomy patients. Acta Chir. Belg. 2020, 1-7. [CrossRef] [PubMed]

3. Rivera, C.; Arame, A.; Pricopi, C.; Riquet, M.; Mangiameli, G.; Abdennadher, M.; Dahan, M.; Barthes, F.L.P. Pneumonectomy for benign disease: Indications and postoperative outcomes, a nationwide study. Eur. J. Cardio Thorac. Surg. 2015, 48, 435-440. [CrossRef] [PubMed]

4. Stolz, A.J.; Harustiak, T.; Simonek, J.; Schutzner, J.; Lischke, R. Pneumonectomy for non-small cell lung cancer: Predictors of early mortality and morbidity. Acta Chir. Belg. 2014, 114, 25-30. [CrossRef]

5. Yang, C.-F.J.; Shah, S.A.; Lin, B.K.; VanDusen, K.W.; Chan, D.Y.; Tan, W.D.; Ranney, D.N.; Cox, M.L.; D'Amico, T.A.; Berry, M.F. Right-Sided Versus Left-Sided Pneumonectomy After Induction Therapy for Non-Small Cell Lung Cancer. Ann. Thorac. Surg. 2019, 107, 1074-1081. [CrossRef]

6. Darling, G.E.; Abdurahman, A.; Yi, Q.-L.; Johnston, M.; Waddell, T.K.; Pierre, A.; Keshavjee, S.; Ginsberg, R. Risk of a Right Pneumonectomy: Role of Bronchopleural Fistula. Ann. Thorac. Surg. 2005, 79, 433-437. [CrossRef] 
7. Rakovich, G.; Bussieres, J.; Fréchette, E. Postpneumonectomy syndrome. Multimed. Man. Cardio Thorac. Surg. 2009, 2009. [CrossRef]

8. Shen, K.R.; Wain, J.C.; Wright, C.D.; Grillo, H.C.; Mathisen, D.J. Postpneumonectomy syndrome: Surgical management and long-term results. J. Thorac. Cardiovasc. Surg. 2008, 135, 1210-1219. [CrossRef]

9. Soll, C.; Hahnloser, D.; Frauenfelder, T.; Russi, E.W.; Weder, W.; Kestenholz, P.B. The postpneumonectomy syndrome: Clinical presentation and treatment. Eur. J. Cardio-Thorac. Surg. 2009, 35, 319-324. [CrossRef]

10. Shiraishi, Y.; Nakajima, Y.; Katsuragi, N.; Kurai, M.; Takahashi, N. Resectional surgery combined with chemotherapy remains the treatment of choice for multidrug-resistant tuberculosis. J. Thorac. Cardiovasc. Surg. 2004, 128, 523-528. [CrossRef]

11. Mohsen, T.; Zeid, A.A.; Haj-Yahia, S. Lobectomy or pneumonectomy for multidrug-resistant pulmonary tuberculosis can be performed with acceptable morbidity and mortality: A seven-year review of a single institution's experience. J. Thorac. Cardiovasc. Surg. 2007, 134, 194-198. [CrossRef]

12. Byun, C.S.; Chung, K.Y.; Narm, K.S.; Lee, J.G.; Hong, D.; Lee, C.Y. Early and Long-term Outcomes of Pneumonectomy for Treating Sequelae of Pulmonary Tuberculosis. Korean J. Thorac. Cardiovasc. Surg. 2012, 45, 110-115. [CrossRef]

13. Kim, Y.T.; Kim, H.K.; Sung, S.-W.; Kim, J.H. Long-term outcomes and risk factor analysis after pneumonectomy for active and sequela forms of pulmonary tuberculosis. Eur. J. Cardio Thorac. Surg. 2003, 23, 833-839. [CrossRef]

14. Matsushima, K.; Aiolfi, A.; Park, C.; Rosen, D.; Strumwasser, A.; Benjamin, E.; Inaba, K.; Demetriades, D. Surgical outcomes after trauma pneumonectomy. J. Trauma Acute Care Surg. 2017, 82, 927-932. [CrossRef]

15. Martin, M.J.; McDonald, J.M.; Mullenix, P.S.; Steele, S.R.; Demetriades, D. Operative Management and Outcomes of Traumatic Lung Resection. J. Am. Coll. Surg. 2006, 203, 336-344. [CrossRef]

16. Phillips, B.; Turco, L.; Mirzaie, M.; Fernandez, C. Trauma pneumonectomy: A narrative review. Int. J. Surg. 2017, 46, 71-74. [CrossRef]

17. Lubitz, A.L.; Sjoholm, L.O.; Goldberg, A.; Pathak, A.; Santora, T.; Sharp, T.E.; Wallner, M.; Berretta, R.M.; Poole, L.A.; Wu, J.; et al Acute right heart failure after hemorrhagic shock and trauma pneumonectomy-A management approach. J. Trauma Acute Care Surg. 2017, 82, 243-251. [CrossRef]

18. Li, Z.; Chen, W.; Xia, M.; Liu, H.; Liu, Y.; Inci, I.; Davoli, F.; Waseda, R.; Filosso, P.L.; White, A. Sleeve lobectomy compared with pneumonectomy for operable centrally located non-small cell lung cancer: A meta-analysis. Transl. Lung Cancer Res. 2019, 8 , 775-786. [CrossRef]

19. Kim, Y.T.; Kang, C.H.; Sung, S.W.; Kim, J.H. Local Control of Disease Related to Lymph Node Involvement in Non-Small Cell Lung Cancer After Sleeve Lobectomy Compared with Pneumonectomy. Ann. Thorac. Surg. 2005, 79, 1153-1161. [CrossRef]

20. Siripurapu, V.; Stitzenberg, K.B.; Nitzkorski, J.; Lebenthal, A.; Scott, W.J. Pneumonectomy for Cancer in the Mid-Atlantic US: Trends and Outcomes over a Decade. Chest 2010, 138, 659A. [CrossRef]

21. Siegel, R.L.; Miller, K.D.; Jemal, A. Cancer statistics, 2020. CA Cancer J. Clin. 2020, 70, 7-30. [CrossRef]

22. Wang, G.; Liu, L.; Zhang, J.; Li, S. The analysis of prognosis factor in patients with non-small cell lung cancer receiving pneumonectomy. J. Thorac. Dis. 2020, 12, 1366-1373. [CrossRef]

23. Ilonen, I.K.; Räsänen, J.V.; Sihvo, E.I.; Knuuttila, A.; Sovijärvi, A.R.; Sintonen, H.; Salo, J.A. Pneumonectomy: Post-operative quality of life and lung function. Lung Cancer 2007, 58, 397-402. [CrossRef]

24. Kris, M.G.; Gaspar, L.E.; Chaft, J.E.; Kennedy, E.B.; Azzoli, C.G.; Ellis, P.M.; Lin, S.H.; Pass, H.I.; Seth, R.; Shepherd, F.A.; et al. Adjuvant Systemic Therapy and Adjuvant Radiation Therapy for Stages I to IIIA Resectable Non-Small-Cell Lung Cancers: American Society of Clinical Oncology/Cancer Care Ontario Clinical Practice Guideline Update Summary. J. Clin. Oncol. 2017, 35, 2960-2974. [CrossRef]

25. Roselli, M.; Mariotti, S.; Ferroni, P.; Laudisi, A.; Mineo, D.; Pompeo, E.; Ambrogi, V.; Mineo, T.C. Postsurgical chemotherapy in stage IB nonsmall cell lung cancer: Long-term survival in a randomized study. Int. J. Cancer 2006, 119, 955-960. [CrossRef]

26. Mineo, T.C.; Ambrogi, V.; Corsaro, V.; Roselli, M. Postoperative adjuvant therapy for stage IB non-small-cell lung cancer. Eur. J. Cardio Thorac. Surg. 2001, 20, 378-384. [CrossRef]

27. Jang, H.J.; Cho, S.; Kim, K.; Jheon, S.; Yang, H.C.; Kim, D.K. Effect of Adjuvant Chemotherapy after Complete Resection for Pathologic Stage IB Lung Adenocarcinoma in High-Risk Patients as Defined by a New Recurrence Risk Scoring Model. Cancer Res. Treat. 2017, 49, 898-905. [CrossRef]

28. Dediu, M.; Ion, O.; Ion, R.; Alexandru, A.; Median, D.; Gal, C.; Horvat, T.; Motas, C.; Motas, N. Impact of adjuvant chemotherapy in stage IB non-small-cell lung cancer: An analysis of 112 consecutively treated patients. JBUON J. Balk. Union Oncol. 2012, 17, 317-322.

29. Park, S.Y.; Lee, J.G.; Kim, J.; Byun, G.E.; Bae, M.K.; Lee, C.Y.; Kim, D.J.; Chung, K.Y. Efficacy of platinum-based adjuvant chemotherapy in T2aN0 stage IB non-small cell lung cancer. J. Cardiothorac. Surg. 2013, 8, 151. [CrossRef]

30. Li, R.; Yang, G.; Tian, Y.; Tian, D. Comparing the benefits of postoperative adjuvant chemotherapy vs. observation for stage IB non-small cell lung cancer: A meta-analysis. J. Thorac. Dis. 2019, 11, 3047-3054. [CrossRef]

31. Arriagada, R.; Auperin, A.; Burdett, S.; Higgins, J.; Johnson, D.; Le Chevalier, T.; Le Pechoux, C.; Mineo, T.; Parmar, M.; Pignon, J.; et al. Adjuvant chemotherapy, with or without postoperative radiotherapy, in operable non-small-cell lung cancer: Two meta-analyses of individual patient data. Lancet 2010, 375, 1267-1277. [CrossRef] [PubMed]

32. Barton, M.K. Adjuvant chemotherapy benefits older and younger non-small cell lung cancer patients alike. CA Cancer J. Clin. 2012, 62, 279-280. [CrossRef] [PubMed] 
33. Batum, Ö.; Anar, C.; Özdoğan, Y.; Ermin, S.; Yllmaz, U. Use of adjuvant chemotherapy for nonsmall cell lung cancer: Is advanced age a prognostic factor? Indian J. Cancer 2018, 55, 282. [CrossRef] [PubMed]

34. Wang, M.; Zhao, J.; Su, Y.-J.; Zhao, X.-L.; Wang, C.-L. Role of adjuvant chemotherapy after pneumonectomy for non-small cell lung cancer. Oncol. Lett. 2012, 4, 1349-1353. [CrossRef]

35. Tsukamoto, S.; Yamazaki, K.; Mori, R.; Katsura, M.; Kouso, H.; Kawano, D.; Ushijima, C.; Takeo, S. Feasibility Study for Biweekly Administration of Cisplatin plus Vinorelbine as Adjuvant-Chemotherapy for Completely Resected Non-Small Cell Lung Cancer Patients in a Japanese Population. Adv. Lung Cancer 2014, 3, 1-9. [CrossRef]

36. Hirai, F.; Seto, T.; Shimokawa, M.; Inamasu, E.; Toyozawa, R.; Toyokawa, G.; Yoshida, T.; Shiraishi, Y.; Takenaka, T.; Yamaguchi, M.; et al. Split-dose cisplatin and vinorelbine as adjuvant chemotherapy for completely resected non-small cell lung cancer. Anticancer. Res. 2014, 34, 927-931.

37. Novello, S. Epidermal Growth Factor Receptor Tyrosine Kinase Inhibitors As Adjuvant Therapy in Completely Resected Non-Small-Cell Lung Cancer. J. Clin. Oncol. 2015, 33, 3985-3986. [CrossRef]

38. Kelly, K.; Altorki, N.K.; Eberhardt, W.E.E.; O’Brien, M.E.; Spigel, D.R.; Crinò, L.; Tsai, C.-M.; Kim, J.-H.; Cho, E.K.; Hoffman, P.C.; et al. Adjuvant Erlotinib Versus Placebo in Patients With Stage IB-IIIA Non-Small-Cell Lung Cancer (RADIANT): A Randomized, Double-Blind, Phase III Trial. J. Clin. Oncol. 2015, 33, 4007-4014. [CrossRef]

39. Wu, Y.-L.; Zhong, W.; Wang, Q.; Xu, S.-T.; Mao, W.-M.; Wu, L.; Shen, Y.; Liu, Y.-Y.; Chen, C.; Cheng, Y.; et al. Gefitinib (G) versus vinorelbine+cisplatin (VP) as adjuvant treatment in stage II-IIIA (N1-N2) non-small-cell lung cancer (NSCLC) with EGFR-activating mutation (ADJUVANT): A randomized, Phase III trial (CTONG 1104). J. Clin. Oncol. 2017, 35, 8500. [CrossRef]

40. Lu, D.; Wang, Z.; Liu, X.; Feng, S.; Dong, X.; Shi, X.; Wang, H.; Wu, H.; Xiong, G.; Wang, H.; et al. Differential effects of adjuvant EGFR tyrosine kinase inhibitors in patients with different stages of non-small-cell lung cancer after radical resection: An updated meta-analysis. Cancer Manag. Res. 2019, 11, 2677-2690. [CrossRef]

41. Wu, Y.-L.; Tsuboi, M.; He, J.; John, T.; Grohe, C.; Majem, M.; Goldman, J.W.; Laktionov, K.; Kim, S.-W.; Kato, T.; et al. Osimertinib in Resected EGFR-Mutated Non-Small-Cell Lung Cancer. N. Engl. J. Med. 2020, 383, 1711-1723. [CrossRef]

42. Raphael, J.; Vincent, M.; Boldt, G.; Shah, P.S.; Rodrigues, G.; Blanchette, P. Adjuvant Epidermal Growth Factor Receptor Tyrosine Kinase Inhibitors (TKIs) in Resected Non-Small Cell Lung Cancer (NSCLC). Am. J. Clin. Oncol. 2019, 42, 440-445. [CrossRef]

43. Huynh, C.; Walsh, L.A.; Spicer, J.D. Surgery after neoadjuvant immunotherapy in patients with resectable non-small cell lung cancer. Transl. Lung Cancer Res. 2021, 10, 563-580. [CrossRef]

44. Brito, A.B.C.; Camandaroba, M.P.G.; de Lima, V.C.C. Anti-PD1 versus anti-PD-L1 immunotherapy in first-line therapy for advanced non-small cell lung cancer: A systematic review and meta-analysis. Thorac. Cancer 2021, 12, 1058-1066. [CrossRef]

45. Robinson, C.G.; Patel, A.; Bradley, J.D.; Waqar, S.N.; Morgensztern, D.; Baggstrom, M.Q.; Govindan, R.; Bell, J.; Guthrie, T.; Colditz, G.A.; et al. Postoperative radiotherapy (PORT) for pathologic N2 non-small cell lung cancer (NSCLC) treated with adjuvant chemotherapy: A review of the National Cancer Database. J. Clin. Oncol. 2014, 32, 7509. [CrossRef]

46. Zeng, W.-Q.; Feng, W.; Xie, L.; Zhang, C.-C.; Yu, W.; Cai, X.-W.; Fu, X.-L. Postoperative Radiotherapy for Resected Stage IIIA-N2 Non-small-cell Lung Cancer: A Population-Based Time-Trend Study. Lung 2019, 197, 741-751. [CrossRef]

47. Corso, C.D.; Rutter, C.E.; Wilson, L.D.; Kim, A.W.; Decker, R.H.; Husain, Z.A. Re-evaluation of the Role of Postoperative Radiotherapy and the Impact of Radiation Dose for Non-Small-Cell Lung Cancer Using the National Cancer Database. J. Thorac. Oncol. 2015, 10, 148-155. [CrossRef] [PubMed]

48. Wang, W.; Men, Y.; Wang, J.; Zhou, Z.; Chen, D.; Xiao, Z.; Feng, Q.; Lv, J.; Liang, J.; Bi, N.; et al. Postoperative radiotherapy is effective in improving survival of patients with stage pIII-N2 non-small-cell lung Cancer after pneumonectomy. BMC Cancer 2019, 19, 478. [CrossRef]

49. Pöttgen, C.; Abu Jawad, J.; Gkika, E.; Freitag, L.; Lübcke, W.; Welter, S.; Gauler, T.; Schuler, M.; Eberhardt, W.E.E.; Stamatis, G.; et al. Accelerated radiotherapy and concurrent chemotherapy for patients with contralateral central or mediastinal lung cancer relapse after pneumonectomy. J. Thorac. Dis. 2015, 7, 264-272.

50. Ayub, A.; Rehmani, S.; Al-Ayoubi, A.M.; Lewis, E.; Santana-Rodríguez, N.; Clavo, B.; Raad, W.; Bhora, F.Y. Radiation therapy improves survival for unresectable postpneumonectomy lung tumors. J. Surg. Res. 2018, 227, 60-66. [CrossRef]

51. Testolin, A.; Favretto, M.S.; Cora, S.; Cavedon, C. Stereotactic body radiation therapy for a new lung cancer arising after pneumonectomy: Dosimetric evaluation and pulmonary toxicity. Br. J. Radiol. 2015, 88, 20150228. [CrossRef] [PubMed]

52. Thompson, R.; Giuliani, M.; Yap, M.L.; Atallah, S.; Le, L.W.; Sun, A.; Brade, A.; Cho, B.J.; Bezjak, A.; Hope, A. Stereotactic Body Radiotherapy in Patients with Previous Pneumonectomy: Safety and Efficacy. J. Thorac. Oncol. 2014, 9, 843-847. [CrossRef]

53. Levra, N.G.; Filippi, A.R.; Guarneri, A.; Badellino, S.; Mantovani, C.; Ruffini, E.; Ricardi, U. Efficacy and Safety of Stereotactic Ablative Radiotherapy in Patients with Previous Pneumonectomy. Tumori J. 2015, 101, 148-153. [CrossRef]

54. Howlader, N.; Noone, A.M.; Krapcho, M.; Miller, D.; Brest, A.; Yu, M.; Ruhl, J.; Tatalovich, Z.; Mariotto, A.; Lewis, D.R.; et al. SEER Cancer Statistics Review, 1975-2017; National Cancer Institute: Bethesda, MD, USA, April 2020. Available online: https:/ / seer.cancer.gov / csr/1975_2017/ (accessed on 20 July 2020).

55. Filosso, P.L.; Guerrera, F.; Lausi, P.O.; Giobbe, R.; Lyberis, P.; Ruffini, E.; Oliaro, A. Pleurectomy/decortication versus extrapleural pneumonectomy: A critical choice. J. Thorac. Dis. 2018, 10, S390-S394. [CrossRef]

56. Magouliotis, D.E.; Tasiopoulou, V.S.; Athanassiadi, K. Updated meta-analysis of survival after extrapleural pneumonectomy versus pleurectomy/decortication in mesothelioma. Gen. Thorac. Cardiovasc. Surg. 2018, 67, 312-320. [CrossRef] 
57. Opitz, I.; Weder, W. A nuanced view of extrapleural pneumonectomy for malignant pleural mesothelioma. Ann. Transl. Med. 2017, 5, 237. [CrossRef]

58. Marulli, G.; Faccioli, E.; Bellini, A.; Mammana, M.; Rea, F. Induction chemotherapy vs post-operative adjuvant therapy for malignant pleural mesothelioma. Expert Rev. Respir. Med. 2017, 11, 649-660. [CrossRef]

59. Cao, C.; Tian, D.; Manganas, C.; Matthews, P.; Yan, T.D. Systematic review of trimodality therapy for patients with malignant pleural mesothelioma. Ann. Cardiothorac. Surg. 2012, 1, 428-437. [CrossRef]

60. Takigawa, N.; Kiura, K.; Kishimoto, T. Medical Treatment of Mesothelioma: Anything New? Curr. Oncol. Rep. 2011, 13, $265-271$. [CrossRef]

61. Tsao, A.S.; Wistuba, I.; Roth, J.A.; Kindler, H.L. Malignant Pleural Mesothelioma. J. Clin. Oncol. 2009, 27, 2081-2090. [CrossRef]

62. Mancuso, M.R.; Neal, J.W. Novel systemic therapy against malignant pleural mesothelioma. Transl. Lung Cancer Res. 2017, 6 , 295-314. [CrossRef]

63. Ambrogi, V.; Baldi, A.; Schillaci, O.; Mineo, T.C. Clinical Impact of Extrapleural Pneumonectomy for Malignant Pleural Mesothelioma. Ann. Surg. Oncol. 2011, 19, 1692-1699. [CrossRef]

64. Batirel, H.F.; Metintas, M.; Caglar, H.B.; Yildizeli, B.; Lacin, T.; Bostanci, K.; Akgul, A.G.; Evman, S.; Yuksel, M. Trimodality Treatment of Malignant Pleural Mesothelioma. J. Thorac. Oncol. 2008, 3, 499-504. [CrossRef] [PubMed]

65. Chen, S.E.; Pace, M.B.; Daniels, L.M.; Raasch, R.H.; Corbett, A.H. Malignant pleural mesothelioma. Am. J. Health Pharm. 2012, 69, 377-385. [CrossRef]

66. Patel, P.R.; Yoo, S.; Broadwater, G.; Marks, L.B.; Miles, E.F.; D’Amico, T.A.; Harpole, D.; Kelsey, C.R. Effect of Increasing Experience on Dosimetric and Clinical Outcomes in the Management of Malignant Pleural Mesothelioma With Intensity-Modulated Radiation Therapy. Int. J. Radiat. Oncol. 2012, 83, 362-368. [CrossRef]

67. Tonoli, S.; Vitali, P.; Scotti, V.; Bertoni, F.; Spiazzi, L.; Ghedi, B.; Buonamici, F.B.; Marrazzo, L.; Guidi, G.; Meattini, I.; et al. Adjuvant radiotherapy after extrapleural pneumonectomy for mesothelioma. Prospective analysis of a multi-institutional series. Radiother. Oncol. 2011, 101, 311-315. [CrossRef]

68. Luckraz, H.; Rahman, M.; Patel, N.; Szafranek, A.; Gibbs, A.R.; Butchart, E.G. Three decades of experience in the surgical multi-modality management of pleural mesothelioma. Eur. J. Cardio-Thorac. Surg. 2010, 37, 552-556. [CrossRef]

69. Garland, L.L.; Rankin, C.; Gandara, D.R.; Rivkin, S.E.; Scott, K.M.; Nagle, R.B.; Klein-Szanto, A.J.; Testa, J.R.; Altomare, D.A.; Borden, E.C. Phase II Study of Erlotinib in Patients With Malignant Pleural Mesothelioma: A Southwest Oncology Group Study. J. Clin. Oncol. 2007, 25, 2406-2413. [CrossRef]

70. Govindan, R.; Kratzke, R.A.; Herndon, J.E.; Niehans, G.A.; Vollmer, R.; Watson, D.; Green, M.R.; Kindler, H.L. Gefitinib in Patients with Malignant Mesothelioma: A Phase II Study by the Cancer and Leukemia Group B. Clin. Cancer Res. 2005, 11, $2300-2304$. [CrossRef]

71. Jackman, D.M.; Kindler, H.L.; Yeap, B.Y.; Fidias, P.; Salgia, R.; Lucca, J.; Morse, L.K.; Ostler, P.A.; Johnson, B.E.; Jänne, P.A. Erlotinib plus bevacizumab in previously treated patients with malignant pleural mesothelioma. Cancer 2008, 113, 808-814. [CrossRef]

72. Porta, C.; Mutti, L.; Tassi, G. Negative results of an Italian Group for Mesothelioma (G.I.Me.) pilot study of single-agent imatinib mesylate in malignant pleural mesothelioma. Cancer Chemother. Pharmacol. 2006, 59, 149-150. [CrossRef] [PubMed]

73. Dudek, A.Z.; Pang, H.; Kratzke, R.A.; Otterson, G.A.; Hodgson, L.; Vokes, E.E.; Kindler, H.L. Phase II Study of Dasatinib in Patients with Previously Treated Malignant Mesothelioma (Cancer and Leukemia Group B 30601): A Brief Report. J. Thorac. Oncol. 2012, 7, 755-759. [CrossRef] [PubMed]

74. Zalcman, G.; Mazieres, J.; Margery, J.; Greillier, L.; Audigier-Valette, C.; Moro-Sibilot, D.; Molinier, O.; Corre, R.; Monnet, I.; Gounant, V.; et al. Bevacizumab for newly diagnosed pleural mesothelioma in the Mesothelioma Avastin Cisplatin Pemetrexed Study (MAPS): A randomised, controlled, open-label, phase 3 trial. Lancet 2016, 387, 1405-1414. [CrossRef]

75. Grosso, F.; Steele, N.; Novello, S.; Nowak, A.K.; Popat, S.; Greillier, L.; John, T.; Leighl, N.B.; Reck, M.; Taylor, P.; et al. Nintedanib Plus Pemetrexed/Cisplatin in Patients With Malignant Pleural Mesothelioma: Phase II Results From the Randomized, Placebo-Controlled LUME-Meso Trial. J. Clin. Oncol. 2017, 35, 3591-3600. [CrossRef]

76. Scagliotti, G.V.; Gaafar, R.; Nowak, A.K.; Nakano, T.; van Meerbeeck, J.; Popat, S.; Vogelzang, N.J.; Grosso, F.; Aboelhassan, R.; Jakopovic, M.; et al. Nintedanib in combination with pemetrexed and cisplatin for chemotherapy-naive patients with advanced malignant pleural mesothelioma (LUME-Meso): A double-blind, randomised, placebo-controlled phase 3 trial. Lancet Respir. Med. 2019, 7, 569-580. [CrossRef]

77. Tsao, A.S.; Miao, J.; Wistuba, I.I.; Vogelzang, N.J.; Heymach, J.V.; Fossella, F.V.; Lu, C.; Velasco, M.R.; Box-Noriega, B.; Hueftle, J.G.; et al. Phase II Trial of Cediranib in Combination With Cisplatin and Pemetrexed in Chemotherapy-Naïve Patients With Unresectable Malignant Pleural Mesothelioma (SWOG S0905). J. Clin. Oncol. 2019, 37, 2537-2547. [CrossRef]

78. Alley, E.W.; Lopez, J.; Santoro, A.; Morosky, A.; Saraf, S.; Piperdi, B.; van Brummelen, E. Clinical safety and activity of pembrolizumab in patients with malignant pleural mesothelioma (KEYNOTE-028): Preliminary results from a non-randomised, open-label, phase $1 \mathrm{~b}$ trial. Lancet Oncol. 2017, 18, 623-630. [CrossRef]

79. Metaxas, Y.; Rivalland, G.; Mauti, L.A.; Klingbiel, D.; Kao, S.; Schmid, S.; Nowak, A.K.; Gautschi, O.; Bartnick, T.; Hughes, B.G.; et al. Pembrolizumab as Palliative Immunotherapy in Malignant Pleural Mesothelioma. J. Thorac. Oncol. 2018, 13, 1784-1791. [CrossRef] 
80. Okada, M.; Kijima, T.; Aoe, K.; Kato, T.; Fujimoto, N.; Nakagawa, K.; Takeda, Y.; Hida, T.; Kanai, K.; Imamura, F.; et al. Clinical Efficacy and Safety of Nivolumab: Results of a Multicenter, Open-label, Single-arm, Japanese Phase II study in Malignant Pleural Mesothelioma (MERIT). Clin. Cancer Res. 2019, 25, 5485-5492. [CrossRef]

81. Quispel-Janssen, J.; van der Noort, V.; de Vries, J.F.; Zimmerman, M.; Lalezari, F.; Thunnissen, E.; Monkhorst, K.; Schouten, R.; Schunselaar, L.; Disselhorst, M.; et al. Programmed Death 1 Blockade With Nivolumab in Patients With Recurrent Malignant Pleural Mesothelioma. J. Thorac. Oncol. 2018, 13, 1569-1576. [CrossRef]

82. Hassan, R.; Thomas, A.; Nemunaitis, J.J.; Patel, M.R.; Bennouna, J.; Chen, F.L.; Delord, J.-P.; Dowlati, A.; Kochuparambil, S.T.; Taylor, M.H.; et al. Efficacy and safety of avelumab treatment in patients with advanced unresectable mesothelioma: Phase $1 \mathrm{~b}$ results from the JAVELIN solid tumor trial. JAMA Oncol. 2019, 5, 351-357. [CrossRef]

83. Popat, S.; Curioni-Fontecedro, A.; Dafni, U.; Shah, R.; O’Brien, M.; Pope, A.; Fisher, P.; Spicer, J.; Roy, A.; Gilligan, D.; et al. A multicentre randomised phase III trial comparing pembrolizumab versus single-agent chemotherapy for advanced pre-treated malignant pleural mesothelioma: The European Thoracic Oncology Platform (ETOP 9-15) PROMISE-meso trial. Ann. Oncol. 2020, 31, 1734-1745. [CrossRef]

84. Disselhorst, M.J.; Quispel-Janssen, J.; Lalezari, F.; Monkhorst, K.; de Vries, J.F.; van der Noort, V.; Harms, E.; Burgers, S.; Baas, P. Ipilimumab and nivolumab in the treatment of recurrent malignant pleural mesothelioma (INITIATE): Results of a prospective, single-arm, phase 2 trial. Lancet Respir. Med. 2019, 7, 260-270. [CrossRef]

85. Scherpereel, A.; Mazieres, J.; Greillier, L.; Lantuejoul, S.; Dô, P.; Bylicki, O.; Monnet, I.; Corre, R.; Audigier-Valette, C.; LocatelliSanchez, M.; et al. Nivolumab or nivolumab plus ipilimumab in patients with relapsed malignant pleural mesothelioma (IFCT-1501 MAPS2): A multicentre, open-label, randomised, non-comparative, phase 2 trial. Lancet Oncol. 2019, 20, 239-253. [CrossRef]

86. Calabrò, L.; Morra, A.; Giannarelli, D.; Amato, G.; D’Incecco, A.; Covre, A.; Lewis, A.; Rebelatto, M.C.; Danielli, R.; Altomonte, M.; et al. Tremelimumab combined with durvalumab in patients with mesothelioma (NIBIT-MESO-1): An open-label, nonrandomised, phase 2 study. Lancet Respir. Med. 2018, 6, 451-460. [CrossRef]

87. Baldini, E.H.; Richards, W.G.; Gill, R.R.; Goodman, B.M.; Winfrey, O.K.; Eisen, H.M.; Mak, R.H.; Chen, A.B.; Kozono, D.E.; Bueno, R.; et al. Updated patterns of failure after multimodality therapy for malignant pleural mesothelioma. J. Thorac. Cardiovasc. Surg. 2015, 149, 1374-1381. [CrossRef]

88. Kostron, A.; Friess, M.; Crameri, O.; Inci, I.; Schneiter, D.; Hillinger, S.; Stahel, R.; Weder, W.; Opitz, I. Relapse pattern and second-line treatment following multimodality treatment for malignant pleural mesothelioma. Eur. J. Cardio-Thorac. Surg. 2015, 49, 1516-1523. [CrossRef]

89. Soldera, S.V.; Kavanagh, J.; Pintilie, M.; Leighl, N.B.; De Perrot, M.; Cho, J.; Hope, A.; Feld, R.; Bradbury, P.A. Systemic Therapy Use and Outcomes After Relapse from Preoperative Radiation and Extrapleural Pneumonectomy for Malignant Pleural Mesothelioma. Oncologist 2019, 24, e510-e517. [CrossRef]

90. WHO. Rapid Communication: Key Changes to Treatment of Drug-resistant Tuberculosis; WHO/CDS/TB/2019.26; World Health Organization: Geneva, Switzerland, December 2019.

91. WHO. Global Tuberculosis Report 2019; World Health Organization: Geneva, Switzerland, 2019.

92. Talwar, A.; Tsang, C.A.; Price, S.F.; Pratt, R.H.; Walker, W.L.; Schmit, K.M.; Langer, A.J. Tuberculosis-United States, 2018. MMWR. Morb. Mortal. Wkly. Rep. 2019, 68, 257-262. [CrossRef]

93. Dewan, R.K.; Pezzella, A.T. Surgical aspects of pulmonary tuberculosis: An update. Asian Cardiovasc. Thorac. Ann. 2016, 24, 835-846. [CrossRef]

94. Yablonskii, P.K.; Kudriashov, G.G.; Avetisyan, A.O. Surgical Resection in the Treatment of Pulmonary Tuberculosis. Thorac. Surg. Clin. 2019, 29, 37-46. [CrossRef]

95. Yablonskiy, P.K.; Vasil'ev, I.V.; Kirjuhina, L.D. Immediate results of pneumonectomies in patients with unilateral localization of destructive pulmonary tuberculosis. Results of the prospective, non-randomized study. Med. Al'yans 2017, 4, 103-111. (In Russian)

96. Harris, R.C.; Khan, M.S.; Martin, L.J.; Allen, V.; Moore, D.A.J.; Fielding, K.; Grandjean, L. The effect of surgery on the outcome of treatment for multidrug-resistant tuberculosis: A systematic review and meta-analysis. BMC Infect. Dis. 2016, 16, 262. [CrossRef]

97. Vashakidze, S.; Gogishvili, S.; Nikolaishvili, K.; Dzidzikashvili, N.; Tukvadze, N.; Blumberg, H.M.; Kempker, R.R. Favorable outcomes for multidrug and extensively drug resistant tuberculosis patients undergoing surgery. Ann. Thorac. Surg. 2013, 95, 1892-1898. [CrossRef]

98. Kang, M.-W.; Kim, H.K.; Choi, Y.S.; Kim, K.; Shim, Y.M.; Koh, W.-J.; Kim, J. Surgical Treatment for Multidrug-Resistant and Extensive Drug-Resistant Tuberculosis. Ann. Thorac. Surg. 2010, 89, 1597-1602. [CrossRef]

99. Yaldiz, S.; Gursoy, S.; Ucvet, A.; Kaya, S.O. Surgery Offers High Cure Rates in Multidrug-resistant Tuberculosis. Ann. Thorac. Cardiovasc. Surg. 2011, 17, 143-147. [CrossRef]

100. Shiraishi, Y.; Katsuragi, N.; Kita, H.; Tominaga, Y.; Kariatsumari, K.; Onda, T. Aggressive surgical treatment of multidrug-resistant tuberculosis. J. Thorac. Cardiovasc. Surg. 2009, 138, 1180-1184. [CrossRef]

101. Wang, H.; Lin, H.; Jiang, G. Pulmonary Resection in the Treatment of Multidrug-Resistant Tuberculosis: A Retrospective Study of 56 Cases. Ann. Thorac. Surg. 2008, 86, 1640-1645. [CrossRef]

102. Kir, A.; Inci, I.; Torun, T.; Atasalihi, A.; Tahaoglu, K. Adjuvant resectional surgery improves cure rates in multidrug-resistant tuberculosis. J. Thorac. Cardiovasc. Surg. 2006, 131, 693-696. [CrossRef] 
103. Naidoo, R.; Reddi, A. Lung Resection for Multidrug-Resistant Tuberculosis. Asian Cardiovasc. Thorac. Ann. 2005, 13, 172-174. [CrossRef]

104. Park, S.K.; Lee, C.M.; Heu, J.P.; Song, S.D. A retrospective study for the outcome of pulmonary resection in 49 patients with multidrug-resistant tuberculosis. Int. J. Tuberc. Lung Dis. 2002, 6, 143-149. [PubMed]

105. Lakshmanan, M.; Xavier, A.S. Bedaquiline-The first ATP synthase inhibitor against multi drug resistant tuberculosis. J. Young Pharm. 2013, 5, 112-115. [CrossRef] [PubMed]

106. Charan, J.; Reljic, T.; Kumar, A. Bedaquiline versus placebo for management of multiple drug-resistant tuberculosis: A systematic review. Indian J. Pharmacol. 2016, 48, 186-191. [CrossRef] [PubMed]

107. Salinger, D.H.; Nedelman, J.R.; Mendel, C.; Spigelman, M.; Hermann, D.J. Daily Dosing for Bedaquiline in Patients with Tuberculosis. Antimicrob. Agents Chemother. 2019, 63, 11. [CrossRef]

108. Diacon, A.H.; Dawson, R.; Hanekom, M.; Narunsky, K.; Venter, A.; Hittel, N.; Geiter, L.J.; Wells, C.D.; Paccaly, A.J.; Donald, P.R. Early bactericidal activity of delamanid (OPC-67683) in smear-positive pulmonary tuberculosis patients. Int. J. Tuberc. Lung Dis. 2011, 15, 949-954. [CrossRef]

109. Conradie, F.; Diacon, A.H.; Ngubane, N.; Howell, P.; Everitt, D.; Crook, A.M.; Mendel, C.M.; Egizi, E.; Moreira, J.; Timm, J.; et al. Treatment of Highly Drug-Resistant Pulmonary Tuberculosis. N. Engl. J. Med. 2020, 382, 893-902. [CrossRef]

110. Eren, S..; Eren, M.N.; Balc1, A.E. Pneumonectomy in children for destroyed lung and the long-term consequences. J. Thorac. Cardiovasc. Surg. 2003, 126, 574-581. [CrossRef]

111. Bai, L.; Hong, Z.; Gong, C.; Yan, D.; Liang, Z. Surgical treatment efficacy in 172 cases of tuberculosis-destroyed lungs. Eur. J. Cardio-Thorac. Surg. 2011, 41, 335-340. [CrossRef]

112. Luzzi, L.; Tenconi, S.; Voltolini, L.; Paladini, P.; Ghiribelli, C.; Di Bisceglie, M.; Gotti, G. Long-term respiratory functional results after pneumonectomy. Eur. J. Cardio-Thorac. Surg. 2008, 34, 164-168. [CrossRef]

113. Fernández, L.G.; Isbell, J.M.; Jones, D.R.; Laubach, V.E. Compensatory lung growth after pneumonectomy. In Topics in Thoracic Surgery; Guerreiro, C., Paulo, F., Eds.; IntechOpen: Sao Pablo, Brazil, 2012; pp. 415-431.

114. Kaza, A.K.; Laubach, V.E.; Kern, J.A.; Long, S.M.; Fiser, S.M.; Tepper, J.A.; Nguyen, R.P.; Shockey, K.S.; Tribble, C.G.; Kron, I.L. Epidermal growth factor augments postpneumonectomy lung growth. J. Thorac. Cardiovasc. Surg. 2000, 120, 916-922. [CrossRef]

115. Dao, D.T.; Anez-Bustillos, L.; Adam, R.M.; Puder, M.; Bielenberg, D.R. Heparin-Binding Epidermal Growth Factor-Like Growth Factor as a Critical Mediator of Tissue Repair and Regeneration. Am. J. Pathol. 2018, 188, 2446-2456. [CrossRef]

116. Matsui, Y.; Amano, H.; Ito, Y.; Eshima, K.; Tamaki, H.; Ogawa, F.; Iyoda, A.; Shibuya, M.; Kumagai, Y.; Satoh, Y.; et al. The role of vascular endothelial growth factor receptor-1 signaling in compensatory contralateral lung growth following unilateral pneumonectomy. Lab. Investig. 2015, 95, 456-468. [CrossRef]

117. Sakurai, M.K.; Lee, S.; Arsenault, D.A.; Nose, V.; Wilson, J.M.; Heymach, J.V.; Puder, M. Vascular endothelial growth factor accelerates compensatory lung growth after unilateral pneumonectomy. Am. J. Physiol. Cell. Mol. Physiol. 2007, 292, L742-L747. [CrossRef]

118. Kaza, A.K.; Kron, I.L.; Leuwerke, S.M.; Tribble, C.G.; E Laubach, V. Keratinocyte growth factor enhances post-pneumonectomy lung growth by alveolar proliferation. Circulation 2002, 106, I-120.

119. Sakamaki, Y.; Matsumoto, K.; Mizuno, S.; Miyoshi, S.; Matsuda, H.; Nakamura, T. Hepatocyte Growth Factor Stimulates Proliferation of Respiratory Epithelial Cells during Postpneumonectomy Compensatory Lung Growth in Mice. Am. J. Respir. Cell Mol. Biol. 2002, 26, 525-533. [CrossRef]

120. Dao, D.T.; Anez-Bustillos, L.; Jabbouri, S.S.; Pan, A.; Kishikawa, H.; Mitchell, P.D.; Fell, G.L.; Baker, M.A.; Watnick, R.S.; Chen, H.; et al. A paradoxical method to enhance compensatory lung growth: Utilizing a VEGF inhibitor. PLoS ONE 2018, 13, e0208579. [CrossRef]

121. Dane, D.M.; Yilmaz, C.; Gyawali, D.; Iyer, R.; Menon, J.U.; Nguyen, K.T.; Ravikumar, P.; Estrera, A.S.; Hsia, C.C.W. Erythropoietin inhalation enhances adult canine alveolar-capillary formation following pneumonectomy. Am. J. Physiol. Cell. Mol. Physiol. 2019, 316, L936-L945. [CrossRef]

122. Takahashi, Y.; Izumi, Y.; Kohno, M.; Kimura, T.; Kawamura, M.; Okada, Y.; Nomori, H.; Ikeda, E. Thyroid Transcription Factor-1 Influences the Early Phase of Compensatory Lung Growth in Adult Mice. Am. J. Respir. Crit. Care Med. 2010, 181, 1397-1406. [CrossRef]

123. Takahashi, Y.; Izumi, Y.; Kohno, M.; Kawamura, M.; Ikeda, E.; Nomori, H. Airway administration of dexamethasone, $3^{\prime}-5^{\prime}$-cyclic adenosine monophosphate, and isobutylmethylxanthine facilitates compensatory lung growth in adult mice. Am. J. Physiol. Cell. Mol. Physiol. 2011, 300, L453-L461. [CrossRef]

124. Lechner, A.J.; Driver, I.H.; Lee, J.; Conroy, C.M.; Nagle, A.; Locksley, R.M.; Rock, J.R. Recruited Monocytes and Type 2 Immunity Promote Lung Regeneration following Pneumonectomy. Cell Stem Cell 2017, 21, 120-134. [CrossRef]

125. Mammoto, T.; Chen, Z.; Jiang, A.; Jiang, E.; Ingber, N.E.; Mammoto, A. Acceleration of Lung Regeneration by Platelet-Rich Plasma Extract through the Low-Density Lipoprotein Receptor-Related Protein 5-Tie2 Pathway. Am. J. Respir. Cell Mol. Biol. 2016, 54, 103-113. [CrossRef]

126. Edvardsen, E.; Skjonsberg, O.H.; Holme, I.; Nordsletten, L.; Borchsenius, F.; Anderssen, S.A. High-intensity training following lung cancer surgery: A randomised controlled trial. Thorax 2015, 70, 244-250. [CrossRef]

127. Kendall, F.; Abreu, P.; Pinho, P.; Oliveira, J.; Bastos, P. The role of physiotherapy in patients undergoing pulmonary surgery for lung cancer. A literature review. Rev. Port. De Pneumol. 2017, 23, 343-351. [CrossRef] 
128. Skrzypczak, P.J.; Roszak, M.; Kasprzyk, M.; Kopczyńska, A.; Gabryel, P.; Dyszkiewicz, W. Pneumonectomy-permanent injury or still effective method of treatment? Early and long-term results and quality of life after pneumonectomy due to non-small cell lung cancer. Pol. J. Cardio-Thorac. Surg. 2019, 16, 7-12. [CrossRef]

129. Lindner, M.; Hapfelmeier, A.; Morresi-Hauf, A.; Schmidt, M.; Hatz, R.; Winter, H. Bronchial Stump Coverage and Postpneumonectomy Bronchopleural Fistula. Asian Cardiovasc. Thorac. Ann. 2010, 18, 443-449. [CrossRef]

130. Mazzella, A.; Pardolesi, A.; Maisonneuve, P.; Petrella, F.; Galetta, D.; Gasparri, R.; Spaggiari, L. Bronchopleural Fistula After Pneumonectomy: Risk Factors and Management, Focusing on Open-Window Thoracostomy. Semin. Thorac. Cardiovasc. Surg. 2018, 30, 104-113. [CrossRef] 